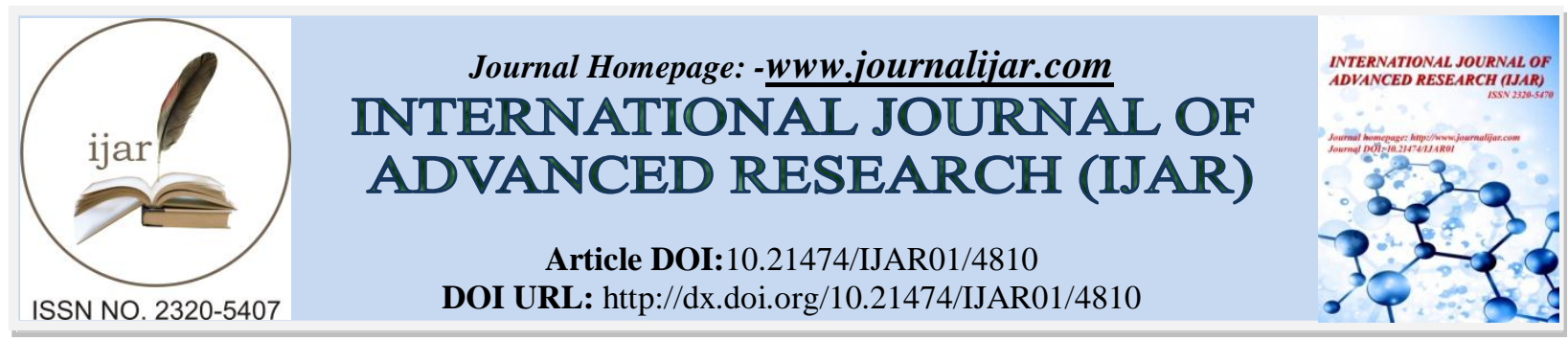

RESEARCH ARTICLE

\title{
RISK FACTORS OF SEVERE ACUTE MALNUTRITION AMONG CHILDREN UNDER FIVE YEARS OF AGE ADMITTED IN THE INDIRA GANDHI CHILD HEALTH AND MIWAND HOSPITALS OF KABUL CITY, AND PARWAN PROVINCIAL HOSPITAL OF AFGHANISTAN.
}

Ahmadwali Aminee.

Student of MPH-Batch 2015-17at School of Public Health, Maulana Azad University Jodhpur, India.

\section{Manuscript Info}

Manuscript History

Received: 10 May 2017

Final Accepted: 12 June 2017

Published: July 2017

\section{Abstract}

Background: Severe Acute Malnutrition among children 0-59 months of age is a serious public health problem in Afghanistan, the 2013 National Nutrition Survey data reviled high wasting rates of $9.5 \%$ (WHZ<-2) (4\% of them are severely wasted WHZ<-3) among children under five at the national level, while the data at provincial level is fluctuating for higher and lower than national figures, which is the leading causes of mortality and morbidity among children under five years of age. This study was conducted in three Therapeutic Feeding Unites located in two tertiary hospital of Kabul city (Indira Gandhi Child Health and Miwand Hospitals) and one provincial hospital in Parwan province of Afghanistan. The objective of the study was to identify the risk factors contributing to severe acute malnutrition among children 0-59 months of age.

Method: This cross-sectional hospital based study was conducted on 301 children with severe acute malnutrition hospitalized in three mentioned therapeutic feeding unites during 4 month (March-June 2017) period. The WHO classifications for severe acute malnutrition (weight for height $<-3 \mathrm{z}$-score or bilateral petting edema) were used to identify children 0-59 months of age with severe acute malnutrition.

Results: out of 301 children under five years with severe acute malnutrition $53.8 \%(n=162)$ were boys and $46.2 \%(n=139)$ were girls. Most of the children $(40 \%)$ were with the age of $=<6$ month, and $60.1 \%(n=184)$ of them were delivered at home. About $46.2 \%(n=139)$ of children had birth weight less than 2500 grams which indicting low birthweight, about $84.1 \%$ of children $(n=253)$ were wasted (severe acute malnutrition with weight for height <-3 ZScore), while only 15.9 $\%$ of them $(\mathrm{n}=48)$ with bilateral petting edema (which is more severe than the first one). $88.4 \%(n=266)$ of children were breastfed during the first 6 months of age (any time) and $11.6 \%(\mathrm{n}=35)$ were reported never breastfeed. Over all $44.5 \%(n=134)$ children reported start complementary feeding during the first 3 month of age , $26.9 \%(\mathrm{n}=$ 81) started between $4-5$ months , $8.6 \%(\mathrm{n}=26)$ between $9-12$ months, and only $19.9 \%(\mathrm{n}=60)$ of children started complementary feeding with the age of 6-8 months which is appropriate time. About $16.3 \%$ had diarrhea, $5.3 \%$ Pneumonia and $1 \%$ Congenital Heart Disease. 
$60.5 \%(\mathrm{n}=182)$ of mothers reported had not completed expected child routine vaccinations. About $34.2 \%(\mathrm{n}=103)$ of mothers had young age (less than 21 year old), and about $83.1 \%(\mathrm{n}=250)$ of mothers were illiterate. $72.8 \%(n=219)$ of mothers had less than 3 or no antenatal visits at all during her pregnancy with the current hospitalized child. The mother knowledge about health and nutrition topics were very low, among all only $17.3 \%(n=52)$ of mothers had information /education about diarrhea, $21.9 \%(\mathrm{n}=66)$ about breastfeeding and.13.3\% $(\mathrm{n}=40)$ about healthy eating. $25 \%(n=75)$ of mothers reported their household income source is from regular wage /salary, and $49.2 \%(\mathrm{n}=148)$ of mothers reported their household monthly income were between 600110000 Afs( 89 - 150 USD). Out of 301 mothers interviewed, $44.2 \%$ $(n=133)$ reported 7-9 family members depended on the monthly income in the household, while $14 \%(\mathrm{n}=42)$ reported $10-12$ people are dependent in the household monthly income. Around $29.6 \%(\mathrm{n}=89)$ mothers reported using stream water for drinking and preparing of foods.

Conclusion: according to the finding of study, mother's education level, access to health care services, mother's knowledge on breastfeeding and starting timely complementary feeding and family income may be the main risk factors contributing on development of severe acute malnutrition among children less than 5 years of age.

Copy Right, IJAR, 2017, All rights reserved.

\section{Introduction:-}

\section{Chapter 1: Introduction}

Afghanistan has one of the highest infant and under five mortality rates with 77 \& 97 per 1000 live births respectively in the region, and also Severe acute malnutrition among children 0-59 months of age is a serious public health problem, the 2013 National Nutrition Survey(NNS) [1] data reviled high wasting rates of $9.5 \%$ (WHZ<-2) (4\% of them are severely wasted WHZ<-3) among children under five at the national level while the data at provincial level is fluctuating for higher and lower than national figures, which is the leading causes of mortality and morbidity among children under five years of age.

According to the UNICEF conceptual framework, the causes of under nutrition among children under five years are classified in three categories (1) immediate causes which consist of, inadequate food intake, and disease. (2) Underlying Causes which consist of: household food insecurity, inadequate mother and child care, and inadequate health and environmental care. (3) Basic causes which includes: political and economic structures, and sociocultural environments.

In Afghanistan- according to NNS 2013 [1] results the distribution of acute malnutrition is mostly high in the provinces/areas with food insecurity, low access of people to and provision of health care services and also security instabilities. There are several important programs for case management of acute cases including facility and community based treatments and follow-up of severe cases through health facilities which covering almost $50 \%$ of all severe cases at the meantime several preventive nutrition interventions are also implanting with support of Ministry of Public Health (MoPH) and other stakeholders, but still there is no any data to present the specific risk factors of acute malnutrition among children under five years of age in Afghanistan, so there is strong need for having such data, which will helps the MoPH and other stockholders by conceding the factors will decrease the under nutrition rates, and indirectly also will contribute to decrease the infant and under five mortalities in the country.

This study provides accurate and reliable information on risk factors of acute malnutrition among children 0-59 months of age in selected areas, and triggers the conducting of further national representative researches in the area.

\section{Chapter 2: Review of Literature}

\subsection{Introduction}

Risk factor for illness and death are extremely high among young children being affected due to infections, poverty and inadequate diet. Malnutrition increases the risk and worsens the severity of infections. Infants and young 
children are mostly affected by malnutrition as they have increased nutritional needs to support growth. The term malnutrition generally refers both to undernutrition and over nutrition, [2] and in children who are 6-59 months of age, severe acute malnutrition is defined as: [3]

- weight-for-height $\leq-3 \mathrm{Z}$-score, or

- mid-upper-arm circumference (MUAC) $<115 \mathrm{~mm}$, or

- Presence of bilateral edema;

Undernourished children, as well as children with severe malnutrition, have a higher risk of dying than children with an optimal nutritional status.

\subsection{Malnutrition in Developing countries}

The spread of infectious disease and macro- micro nutrient deficiencies are prevalent mainly due to socioeconomical and geographical factors. Globally, it was estimated that one in every three preschool children is malnourished (WHO \&UNICEF 2011), [2] according to the estimation, 165 million children under-five years of age were underweight, 101 million were stunted and another 52 million were wasted. Childhood malnutrition is influenced by multidimensional factors; these factors vary from biological, behavioral and environmental. New estimates in "Levels and Trends in Child Mortality 2014" shows that in 2013, 6.3 million children under five died from mostly preventable causes, around 200,000 fewer than in 2012, but still equal to nearly 17,000 child deaths each day. The improvement of nutrition therefore, is the main prerequisite for the reduction of high infant and under five mortality rates, the assurance of physical growth, social and mental development of children as well as academic achievements.

\subsection{A review of similar studies on child malnutrition}

In 2015 a cross-sectional study under the name of "Risk Factors of Malnutrition among Children under Five Year of Age" was conducted in Mohamed Alamin Paediatric Hospital of Khartoum Sudan [4], the study concluded that the Malnutrition is more prevalent in male children between 1-2 year of age and the low family income were found to be the main factors contributed to malnutrition among children less than five years of age.

Mohammed Ali Badi and Iman Ali Ba-Saddik conducted a cross-sectional study on "Severe Acute Malnutrition among Hospitalized Children" in Aden, Yemen [5]. The study shows that the data available from hospitals only shows the severe cases and therefore malnutrition in general is not always recorded because in most cases it is the secondary diagnosis. There is a greater likelihood that children under one year are probably more prone to malnutrition and require more nutritive care and attention to their health. Because the children are the victims of poverty, political instability and acute deprivation of living facilities, recent droughts in the rural and finally unfavorable nutrition of children all over the governorate are the reasons for the severe acute malnutrition.

A study on "Outcome in malnourished children at a tertiary hospital in Swaziland", [6] was conducted by Dr. Oscar Benyera in 2013, a total of 227 children with acute malnutrition and 175 with severely malnourished and 98 of them with moderate acute malnutrition, during the study found that total of 111 children died during admission and overall the case-fatality rate was $40.1 \%$. Mortality was significantly higher among severely malnourished children compared to those with moderate cases. Comorbid pneumonia and gastroenteritis were significant predictors of mortality.

In 2016 a study on Socio-cultural determinants of Malnutrition among children aged below 5 years was conducted by Maryam Ahmed Abdul Rahim in Garissa Sub County of Kenya [7]. The study was cross-sectional in nature and total of 365 mothers /guardians in Garissa Sub County with children under five years of age were participated in the study, and the findings of the study showed that, the children aged 37-54 months were significantly more wasted $(42.6 \%)$ than children aged 12 months and below (24.8\%), Mother's/guardians age was significantly associated with child wasting. Mothers/guardians aged 16-25 years had significantly higher proportion of children who presented with wasting (29.6\%) compared to those aged 36 years and above (12.5\%). The mother's /guardians education marital status also has significant association with wasting cases of their children, the wasting rate was high among mother's /guardians with low education and married status, the family income was also important factor, the wasting rate was higher among families with low income than those with good income.

In 2012 a case control study was conducted in identify and determine the risk factors for malnutrition among children under the age of 5 years in Kweneng West District of Botswana by Yankinda Etienee Kadima. [8] A total of 113 respondents $(\mathrm{N}=113)$ were recruited in the study, with a total of $33 \%$ cases with underweight $(\mathrm{n}=37)$ and $67 \%$ 
controls with no underweight $(\mathrm{n}=76)$. There were a total of $54(48 \%)$ females in the study, of which $61 \%$ were among the cases and 39\% were among the controls. The results showed that the most contributing factors on malnutrition among children under the age of five years in Kweneng West District of Botswana were as follows:

- Basic causes: parent's unemployment.

- Underlying causes: lack of knowledge of infant and child feeding practices by the parent, inadequate childcare practices, inadequate Vitamin A supplementation, and low birth weight.

- Immediate causes: inadequate dietary intake, and child illness.

A cross-sectional study on Food consumption patterns and nutritional status of children (6-59 months) in Camps of internally displaced persons in Wadajir district, Mogadishu, Somalia was conducted in 2012 by Farhia Abdi Aziz Sh.Hussien [9], the results of the study showed that Malnutrition among children 6-59 months was influenced by many different factors of which, Food consumption, Nutritional status of children 6-59months, sources of food, Nutrition awareness of the care givers and Household size.

Results from a case control study on association between malnutrition and feeding practices among children aged 6-24 month at Mbagathi Distric hospital, Kenya, 2014, revealed that, inappropriate feeding practices of infant and young children impact negatively on their nutritional status. Moreover social economic factors like poor education of the parents, unemployment, poor housing and low house hold income all contribute indirectly to the poor nutrition of the children.

A cross-sectional study on Perceived socio-cultural factors influencing nutritional status of children below the age of of 5 years of age in selected rural communities in Enugu state of Nigeria was conducted by Nnabuenyi Chinyelu J.P. The results of the study revealed that, Malnutrition is a major childhood killer disease and is responsible for over 60 percent of avoidable maternal and infant mortality. Therefore, the socio-cultural factors influencing nutritional status like family structure, socio-economic status, religious and cultural practices.

The results of a study conducted on Immediate Risk Factor Associated with Child Malnutrition in Ghana; A Critical Analysis of the Ashiedu Keteke Sub-Metro Area in Accra, in 2010 ( Abena K. Sarpong, Smart A. Sarpong, Christian Obirikorang, N. N. N. Nsowah-Nuamah)[12] found that the Immunization practices, diseases and infections like diarrhoea, fever, pneumonia, sepsis, meningitis, and sickle cell were considered to be immediate factors contributing to malnutrition together with breastfeeding practices, exclusive breastfeed and birth weight.

A Community Based Matched Case Control Study on Determinants of Severe Acute Malnutrition among Under Five Children in Shashogo Woreda, Southern Ethiopia in 2014 [13] was conducted by Nebiyu Dereje. The findings of the study have confirmed the association of severe acute malnutrition with maternal education, maternal autonomy in decision making and inappropriate infant and young child caring practices.

\section{Chapter 3: Methodology}

\subsection{Study design and population}

The study design is a cross-sectional, and the target population of the study include all children 0-59 months of age with severe acute malnutrition (Weight for Height $<-3 \mathrm{z}$ score or bilateral petting oedema, or mid-upper-arm circumference (MUAC) $<115 \mathrm{~mm}$ ) hospitalized in three Therapeutic Feeding Units (TFUs) which are located in two hospital of Kabul city (Indira Gandhi Child Health Hospital and Miwand Hospitals) and one in Parwan provincial hospital, and the interview was conducted with the mothers/care takers of children.

\subsection{Sampling}

The sampling area was selected as purposive sampling due to fund limitations and inclusion of sites with high admission rate of severe acute malnutrition children with consideration having cases from most part of the country, as the two selected hospital in Kabul city functioning as tertiary hospitals in the country and children with severe acute malnutrition and other medical complications coming to these hospitals from different parts of the country which help as to have an overview of risk factors contributing malnutrition from different part of the country and the second hospital which is functioning at Parwan province located about $100 \mathrm{Km}$ north part of Kabul city will also give us some figures about specific risk factors of acute malnutrition in north part of the country. 


\subsection{Sample size}

The sample size is based on the following assumptions: $95 \%$ confidence interval, precision of 0.05 , design effect of 2 , and response rate of $80 \%$, a target sample size of 304 individual will be interviewed at the above mentioned three TFU sites, at least 102 mothers /care takers of children with acute malnutrition in each site.

\subsection{Questionnaire adaptation, pre-testing and translation}

Prior to data collection, in close consultation with my site supervisor a questionnaire including 33 questions with consideration of Afghanistan context was developed on English language, and pre-tested in an area out of study sites. The aim of the pre-testing was to ensure the logical and correct flow of the questions and that participant understand the questions. Questionnaire was translated into languages and then back translated to English; the back translated version was shared with my site supervisor for review and approval. The final translated was used for data collection.

\subsection{Data collection}

Prior to starting the data collection the relevant authorities in the hospital and provincial health directorate and also provincial nutrition officers were visited to notify and get their approval for study implementation. All interviews with caregivers was administered by trained medical staffs working in the mentioned TFU sites using a structured questionnaire designed to collect nutrition status, health, food habits and knowledge of mothers/care takers about feeding practices of children. All participants have been taken an informed consent (verbally) prior to starting the interview. The data collection was completed within 4 months.

\subsection{Training}

A half day training/orientation was provided to all medical staff involved on data collection and worked in the mentioned TFU sites, the training was included the practices on how to interview mothers/care takers and filling the questioner.

\subsection{Data processing, storage and management}

In close consultation with my site supervisor, an Excel database was developed and a double data entry was applied. One copy of the raw data files was saved without making any changes and another copy of the data files was reviewed for inconsistencies, coding errors, and any other implausible values, checked and cleaned in collaboration with the site supervisor. All differences were verified with paper questionnaires. Additional data cleaning procedures include running frequencies on all variables through SPSS version 23 was applied to identify erroneous entries and those outside of acceptable ranges, as well as missing data.

For confidentiality the data and all questionnaires will be kept in secure place and only authorized persons would have access to the filled questionnaires.

\subsection{Date Analysis}

The data was firstly interred in an Excel based database and for further analysis transferred to SPSS version 23. Basic statistical tests (Frequency table, chi-square p values) were applied.

\subsection{Ethical Consideration}

Prior of starting the study, appropriate approval from relevant departments of the government including Public Nutrition Directorate of MoPH as a portfolio of nutrition programs in the country, and also the directorates of three mentioned hospital where the study sides were located, has been taken. During the interview a verbal consent was also taken from all mothers and caretakers of children participating in the study. Since the sample size of the study is not national representative due fund limitation and shortage of time, the study protocol was not presented to the national IRB (Intuitional Review Board), as first criteria for approval of any study by the board, the study should be national representative.

\subsection{Limitations of the study}

At three mentioned hospitals, the admission of children with severe acute malnutrition were not the same and the data collection take place one month longer than as expected of three months at the beginning. A number of mothers rejected to participate in the study those excluded from the total count. Since all participants were selected from severe acute malnutrition children admitted in the Therapeutic Feeding Unites which limited the analysis of associations between most of variable to verify the association of child malnutrition with the risk factors. 


\section{Chapter 4: Results and Discussions:- \\ 4.1 Introduction}

The focus of this chapter is on the presentation and description of findings of the study, discussion, conclusion and recommendations.

\subsection{Data management and analysis}

Data were collected using a structured questioner, interviewed with mother/caretaker of children with acute severe malnutrition and primarily information about child admission criterion set for classification of acute malnutrition children based on national and WHO classifications. The following basic procedures were carried out before the data were analyzed:

- Data were coded.

- Inconsistencies in the data in the questionnaire were checked for, and if found, were queried with the interviewer.

- Any missing data were documented.

The data was firstly entered in an Excel data based and secondly analyzed using SPSS version 23.

\subsection{Study results}

This section presents a summary of the findings of the study. The results are presented both in descriptive and analytical form, in frequencies, percentages, graphs, figures, tables, and the requisite statistics. The purpose of this study was to find the Risk factors of Severe Acute Malnutrition among children less than five years of age admitted in the Indira Gandhi Child Health and Miwand Hospitals of Kabul city, and Parwan provincial hospital of Afghanistan.

Main focuses area of the study were as follows:

- Information about children less than five years of age with severe acute malnutrition admitted in the mentioned THU sites, including name, birth ringing, place of birth, age, gender, and birth weight, type of acute malnutrition, feeding practices and immunization status and also existing of other disease coherent with severe acute malnutrition.

- Information about mother/caretaker of children with severe acute malnutrition admitted in the mentioned TFUs, including age of the mother, level of education, marital status, attending of mother in ANC visits and knowledge of mother/caretaker about healthy eating, feeding practices and growth monitoring, also if the mother has any disease with current child.

- Socio-economic situation of the family of the children with severe acute malnutrition, including situation of employment of the head of family, source and amount of monthly income of the family, number of people depended on that income, and also source of drinking water of the family.

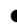

4.3.1 Information about children less than five years of age with severe acute malnutrition A total of 301 children under the age of five years with severe acute malnutrition were participated in the study and the interview was conducted with mothers/caretaker of the children.

\subsubsection{Age, gender, birth ringing and children's place of birth}

About $53.8 \%(n=162 \quad)$ were boys and $46.2 \% \quad(n=139)$ were girls. Out of 301 children around $40 \%(n=119)$ of them had the age of $=<6$ month while children aged from 7-12 months and 13-24 month contributing to $28.4 \%$ and $18.5 \%$ respectively. From the total of 301 children. About $17.6 \%$ of mothers had only one live birth (the child in the study), $27.2 \%$ had two live births, $18.9 \%$ had three live births, and $13.3 \%$ had four live births while $10.6 \%$ had 5 live births and only $12.3 \%$ had more than 5 live births. $60.1 \%(n=184)$ were reported delivered at home and only $38.9 \%(\mathrm{n}=117)$ delivered at any health facilities which indicating intuitional delivery.

Table 4.1 Sex

\begin{tabular}{|l|l|r|r|r|r|}
\hline \multicolumn{2}{|c|}{} & Frequency & Percent & Valid Percent & Cumulative Percent \\
\hline \multirow{3}{*}{ Valid } & Male & 162 & 53.8 & 53.8 & 53.8 \\
\cline { 2 - 6 } & Female & 139 & 46.2 & 46.2 & 100.0 \\
\cline { 2 - 6 } & Total & 301 & 100.0 & 100.0 & \\
\hline
\end{tabular}

Table 4.2 Age in months

\begin{tabular}{|r|l|r|r|r|r|}
\hline \multicolumn{2}{|c|}{} & Frequency & Percent & Valid Percent & Cumulative Percent \\
\hline Valid & $<=6$ & 119 & 39.5 & 39.5 & 39.5 \\
\hline
\end{tabular}




\begin{tabular}{|l|l|r|r|r|r|}
\hline & $7-12$ & 86 & 28.6 & 28.6 & 68.1 \\
\hline $13-24$ & 56 & 18.6 & 18.6 & 86.7 \\
\cline { 2 - 6 } & $25-36$ & 29 & 9.6 & 9.6 & 96.3 \\
\cline { 2 - 6 } & $37-48$ & 10 & 3.3 & 3.3 & 99.7 \\
\cline { 2 - 6 } & $49-59$ & 1 & .3 & .3 & 100.0 \\
\cline { 2 - 6 } & Total & 301 & 100.0 & 100.0 & \\
\hline
\end{tabular}

Table 4.3 Birth ringing

\begin{tabular}{|c|c|c|c|c|c|}
\hline Valid & & Frequency & Percent & Valid Percent & Cumulative Percent \\
\hline & 1 & 53 & 17.6 & 17.6 & 17.6 \\
\hline & 10 & 1 & .3 & .3 & 17.9 \\
\hline & 2 & 82 & 27.2 & 27.2 & 45.2 \\
\hline & 3 & 57 & 18.9 & 18.9 & 64.1 \\
\hline & 4 & 40 & 13.3 & 13.3 & 77.4 \\
\hline & 5 & 32 & 10.6 & 10.6 & 88.0 \\
\hline & 6 & 22 & 7.3 & 7.3 & 95.3 \\
\hline & 7 & 11 & 3.7 & 3.7 & 99.0 \\
\hline & 8 & 2 & .7 & .7 & 99.7 \\
\hline & 9 & 1 & .3 & .3 & 100.0 \\
\hline & Total & 301 & 100.0 & 100.0 & \\
\hline
\end{tabular}

Table 4.4. Place of birth

\begin{tabular}{|c|l|r|r|r|r|}
\hline \multicolumn{2}{|c|}{} & \multicolumn{1}{|c|}{ Frequency } & Percent & Valid Percent & Cumulative Percent \\
\hline Valid & $\begin{array}{l}\text { In hospital /near health } \\
\text { facility }\end{array}$ & 117 & 38.9 & 38.9 & 38.9 \\
\cline { 2 - 6 } & at home & 184 & 61.1 & 61.1 & 100.0 \\
\cline { 2 - 6 } & Total & 301 & 100.0 & 100.0 & \\
\hline
\end{tabular}

\subsubsection{Birth weight and type of severe acute malnutrition}

About $46.2 \%(n=139)$ of children reported had birth weight leas then 2500 grams which indicting low birthweight and $53.8 \%(n=162)$ with normal birth weight. A total of $84.3 \%$ of children $(n=253)$ were wasted (severe acute malnutrition with weight for height <-3 ZScore), while $15.9 \%(\mathrm{~N}=48)$ were admitted with bilateral petting edema (which is more severe than the first one).

\begin{tabular}{|l|l|r|r|r|r|}
\hline \multicolumn{2}{|l|}{ Table 4.5Birth weight } & Frequency & Percent & \multicolumn{1}{|c|}{$\begin{array}{c}\text { Valid } \\
\text { Percent }\end{array}$} & Cumulative Percent \\
\hline \multirow{3}{*}{ Valid } & low birth weight $(<2500 \mathrm{~g})$ & 139 & 46.2 & 46.2 & 46.2 \\
\cline { 2 - 6 } & $\begin{array}{l}\text { Normal birth weight( }>\text { or }= \\
\text { 2500 gr) }\end{array}$ & 162 & 53.8 & 53.8 & 100.0 \\
\cline { 2 - 6 } & Total & 301 & 100.0 & 100.0 & \\
\hline
\end{tabular}

\subsubsection{Feeding practices and immunization status of children}

Out of 301 children participating in the study, majority of children, $88.4 \%(n=266)$ were breastfed during the first 6 months of age (any time) and $11.6 \%(\mathrm{n}=35)$ were reported never breastfeed. Total of $44.5 \%(\mathrm{n}=134)$ children reported start complementary feeding during the first 3 month of age while $26.9 \%(n=81)$ started between $4-5$ months of age and $19.9 \%(n=60)$ of children with age of $6-8$ months, while $8.6 \%(n=26)$ aged between $9-12$ months. About the immunization status, $32.6 \%(n=98)$ of mothers reported completed their child immunization but $60.5 \%(\mathrm{n}=182)$ had not completed the child routine vaccinations.

\begin{tabular}{|c|c|c|c|c|c|}
\hline & & Frequency & Percent & Valid Percent & Cumulative Percent \\
\hline \multirow[t]{2}{*}{ Valid } & Yes(ever breastfed) & 266 & 88.4 & 88.4 & 88.4 \\
\hline & No(never breastfed) & 35 & 11.6 & 11.6 & 100.0 \\
\hline
\end{tabular}




\begin{tabular}{|c|c|c|c|c|c|}
\hline & Total & 301 & 100.0 & 100.0 & \\
\hline \multicolumn{6}{|c|}{ Table 4.7 at what age did the mother introduce solid foods (in months) } \\
\hline & & Frequency & Percent & Valid Percent & Cumulative Percent \\
\hline \multirow[t]{5}{*}{ Valid } & $<=3$ & 134 & 44.5 & 44.5 & 44.5 \\
\hline & $4-5$ & 81 & 26.9 & 26.9 & 71.4 \\
\hline & $6-8$ & 60 & 19.9 & 19.9 & 91.4 \\
\hline & $9-12$ & 26 & 8.6 & 8.6 & 100.0 \\
\hline & Total & 301 & 100.0 & 100.0 & \\
\hline
\end{tabular}

\begin{tabular}{|c|c|c|c|c|c|}
\hline & & Frequency & Percent & Valid Percent & Cumulative Percent \\
\hline \multirow[t]{4}{*}{ Valid } & Up to date & 98 & 32.6 & 32.6 & 32.6 \\
\hline & Not up to date & 182 & 60.5 & 60.5 & 93.0 \\
\hline & Not sure & 21 & 7.0 & 7.0 & 100.0 \\
\hline & Total & 301 & 100.0 & 100.0 & \\
\hline
\end{tabular}

\subsubsection{Information about mother/caretaker of children}

4.3.2.1 Age and higher education level of the mother

The age of mother was classified in two categories, younger age (<21 years) and old age ( $>21$ years), around $34.2 \%(\mathrm{n}=103)$ mothers reported were young and 59.1\% $(\mathrm{n}=178)$ of them had old age. About education level of mothers, $83.1 \%(n=250)$ were reported illiterate and $13.6 \%(n=41)$ reported with primarily education (up to 6 grad of school) and only $2 \%(n=6)$ had tertiary education (graduated from any higher educations).

\begin{tabular}{|c|c|c|c|c|c|}
\hline & & Frequency & Percent & Valid Percent & Cumulative Percent \\
\hline \multirow[t]{4}{*}{ Valid } & Younger age $(<21$ years $)$ & 103 & 34.2 & 34.2 & 34.2 \\
\hline & old age $(>21$ years $)$ & 178 & 59.1 & 59.1 & 93.4 \\
\hline & Unknown & 20 & 6.6 & 6.6 & 100.0 \\
\hline & Total & 301 & 100.0 & 100.0 & \\
\hline
\end{tabular}

\begin{tabular}{|l|l|r|r|r|r|}
\hline \multicolumn{2}{|c|}{ Table 4.10 the mother highest level of education } & \multicolumn{1}{|c|}{$\begin{array}{c}\text { Valid } \\
\text { Percent }\end{array}$} & Cumulative Percent \\
\hline Valid & $\begin{array}{l}\text { Frequency } \\
\text { Illiterate (never been at } \\
\text { school) }\end{array}$ & 250 & 83.1 & 83.1 & 83.1 \\
\cline { 2 - 6 } & $\begin{array}{l}\text { Primary (up to 6 grad of } \\
\text { school) }\end{array}$ & 41 & 13.6 & 13.6 & 96.7 \\
\cline { 2 - 6 } & $\begin{array}{l}\text { Secondary (up to 12 grad } \\
\text { of school) }\end{array}$ & 4 & 1.3 & 1.3 & 98.0 \\
\hline $\begin{array}{l}\text { Tertiary (graduated from } \\
\text { any higher educations) }\end{array}$ & 6 & 2.0 & 2.0 & 100.0 \\
\hline Total & 301 & 100.0 & 100.0 & \\
\hline
\end{tabular}


4.3.2. 2 Material statue and participation of mother to at least 3 antenatal care visits to a near health facility during her pregnancy with the current admitted child

About $98.3 \%$ ( $n=296)$ of mothers were reported marred; and only $27.2 \%(n=82)$ were reported had participated at

Table 4.12 Mother attend at least 3 antenatal care visits while she was pregnant with the current admitted child at the near health facility

\begin{tabular}{|c|c|c|c|c|c|}
\hline & Frequency & Percent & Valid Percent & Cumulative Percent \\
\hline \multirow[t]{3}{*}{ Valid } & Yes & 82 & 27.2 & 27.2 & 27.2 \\
\hline & No & 219 & 72.8 & 72.8 & 100.0 \\
\hline & Total & 301 & 100.0 & 100.0 & \\
\hline
\end{tabular}

least 3 antenatal visits during her pregnancy with the current child while $72.8 \%(n=219)$ of mothers had less than 3 or no antenatal visits at all.

\begin{tabular}{|c|c|c|c|c|c|}
\hline & & Frequency & Percent & Valid Percent & Cumulative Percent \\
\hline \multirow[t]{4}{*}{ Valid } & Married & 296 & 98.3 & 98.3 & 98.3 \\
\hline & Divorced & 2 & .7 & .7 & 99.0 \\
\hline & Widowed & 3 & 1.0 & 1.0 & 100.0 \\
\hline & Total & 301 & 100.0 & 100.0 & \\
\hline
\end{tabular}

4.3.2. 3 Knowledge of mother on Diarrhoea, Healthy eating, breastfeeding, complementary feeding, food fortification and growth monitoring

Only $17.3 \% \quad(n=52)$ of mothers received information /education on diarrhea in the clinic, while other topics including $13.3 \%$ (40) about healthy eating, $21.9 \%(\mathrm{n}=66)$ about breastfeeding, $5.6 \%(\mathrm{n}=17)$ about complementary feeding and almost less than $2 \%$ about food fortification and growth monitoring.

\begin{tabular}{|c|c|c|c|c|c|}
\hline & & Frequency & Percent & Valid Percent & Cumulative Percent \\
\hline \multirow[t]{3}{*}{ Valid } & Yes & 52 & 17.3 & 17.3 & 17.3 \\
\hline & No & 249 & 82.7 & 82.7 & 100.0 \\
\hline & Total & 301 & 100.0 & 100.0 & \\
\hline
\end{tabular}

Table 4.15 the mother received counselling on (Breastfeeding)

\begin{tabular}{|c|c|c|c|c|c|}
\hline & & Frequency & Percent & Valid Percent & Cumulative Percent \\
\hline \multirow[t]{3}{*}{ Valid } & Yes & 66 & 21.9 & 21.9 & 21.9 \\
\hline & No & 235 & 78.1 & 78.1 & 100.0 \\
\hline & Total & 301 & 100.0 & 100.0 & \\
\hline
\end{tabular}

\begin{tabular}{|c|c|c|c|c|c|}
\hline & & Frequency & Percent & Valid Percent & Cumulative Percent \\
\hline \multirow[t]{3}{*}{ Valid } & Yes & 40 & 13.3 & 13.3 & 13.3 \\
\hline & No & 261 & 86.7 & 86.7 & 100.0 \\
\hline & Total & 301 & 100.0 & 100.0 & \\
\hline
\end{tabular}

\begin{tabular}{|c|c|c|c|c|c|}
\hline & & Frequency & Percent & Valid Percent & Cumulative Percent \\
\hline \multirow[t]{3}{*}{ Valid } & Yes & 17 & 5.6 & 5.6 & 5.6 \\
\hline & No & 284 & 94.4 & 94.4 & 100.0 \\
\hline & Total & 301 & 100.0 & 100.0 & \\
\hline
\end{tabular}

4.3.3.3 Income source of the family and average monthly income of the family from all sources, number of people depend on that amount and head of the family

$25 \%(n=75)$ of mothers reported their household income source is from regular wage /salary while $70.8(\mathrm{n}=213)$ reported other sources and only around $4.2 \%$ of families used incomes from pension and disability sources. $49.2 \%$ $(n=148)$ of mothers reported their monthly income were between 6001-10000 Afs( 89 - 150 USD) and about 22.6 
$\% \quad(n=68)$ reported income from 3001-6000Afs (44 - 89 USD) while 19.9\%( $\mathrm{n}=60)$ of women reported their household monthly income was from 10001-15000 Afs( 150-224 USD), while only 5.3\% ( $\mathrm{n}=16$ ) reported their monthly income from 15,001-20,000 (224 -300 USD) and 2,3\% ( $\mathrm{n}=7$ )above from 20001 Afs ( >300 USD).

Out of 301 mothers interviewed, $44.2 \%$ (n=133) reported 7-9 family members depended on the income in the household, while another $37.5 \%(\mathrm{n}=113)$ reported $4-6$ and only $14 \%(\mathrm{n}=42)$ reported $10-12$ are dependent in the household. However, $82.1 \%(\mathrm{n}=247)$ mothers reported the child's father and $17.6 \%(\mathrm{n}=53)$ the father's in-law of the child and only on $0.3 \%(n=1)$ the mother of child was the head of the household.

\begin{tabular}{|c|c|c|c|c|c|}
\hline & & Frequency & Percent & Valid Percent & Cumulative Percent \\
\hline \multirow[t]{9}{*}{ Valid } & $<=3000$ & 2 & .7 & .7 & .7 \\
\hline & $3001-6000$ & 68 & 22.6 & 22.6 & 23.3 \\
\hline & $6001-10000$ & 148 & 49.2 & 49.2 & 72.4 \\
\hline & $10001-15000$ & 60 & 19.9 & 19.9 & 92.4 \\
\hline & $15001-20000$ & 16 & 5.3 & 5.3 & 97.7 \\
\hline & $20001-25000$ & 1 & .3 & .3 & 98.0 \\
\hline & $25001-30000$ & 1 & .3 & .3 & 98.3 \\
\hline & $30001+$ & 5 & 1.7 & 1.7 & 100.0 \\
\hline & Total & 301 & 100.0 & 100.0 & \\
\hline
\end{tabular}

Table 4.18 Head of the household

\begin{tabular}{|l|l|r|r|r|r|}
\hline \multicolumn{2}{|c|}{} & Frequency & \multicolumn{1}{|c|}{ Percent } & Valid Percent & \multicolumn{1}{c|}{ Cumulative Percent } \\
\hline \multirow{7}{*}{ Valid } & Father of the child & 247 & 82.1 & 82.1 & 82.1 \\
\cline { 2 - 6 } & Father in-law of the child & 53 & 17.6 & 17.6 & 99.7 \\
\cline { 2 - 6 } & mother of the child & 1 & .3 & .3 & 100.0 \\
\cline { 2 - 6 } & Total & 301 & 100.0 & 100.0 & \\
\hline
\end{tabular}

Table 4.19 Number of people depend on monthly income of the family

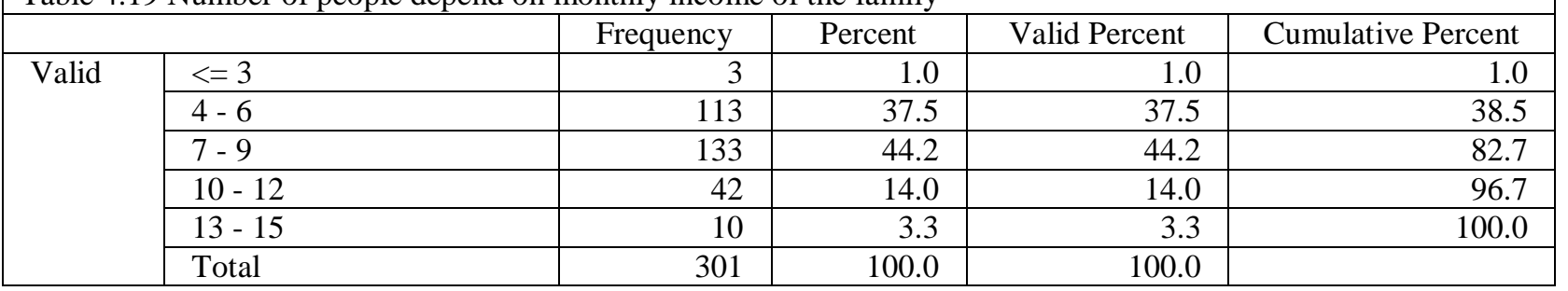

\subsubsection{Family source of water for drinking and preparing foods}

Around $39.5 \%(n=119)$ of mothers/caretakers reported they are using dug well water and $29.6 \%(n=89)$ and 28.2 $\%(n=85)$ reported stream and Piped water respectively and only $1.3 \%$ from spring water $(n=4)$ and $1.3 \%(n=4)$ from other source of water for drinking and preparing of foods.

\begin{tabular}{|l|l|r|r|r|r|}
\hline \multicolumn{2}{|c|}{ Table 4.20 Source of water for drinking and preparing foods of the family } \\
\hline \multirow{4}{*}{ Valid } & Dug Wells & Frequency & Percent & Valid Percent & \multicolumn{1}{c|}{ Cumulative Percent } \\
\cline { 2 - 6 } & Stream water & 119 & 39.5 & 39.5 & 39.5 \\
\cline { 2 - 6 } & Piped water & 85 & 28.2 & 28.2 & 67.8 \\
\cline { 2 - 6 } & Spring water & 89 & 29.6 & 29.6 & 97.3 \\
\cline { 2 - 6 } & other & 4 & 1.3 & 1.3 & 98.7 \\
\cline { 2 - 6 } & Total & 4 & 1.3 & 1.3 & 100.0 \\
\hline
\end{tabular}




\section{Associations Between Variables}

Associations between a numbers of variables are reported in the following sections.

\subsubsection{Type of malnutrition and gender}

Table 4.21Admission criteria * Sex Cross tabulation

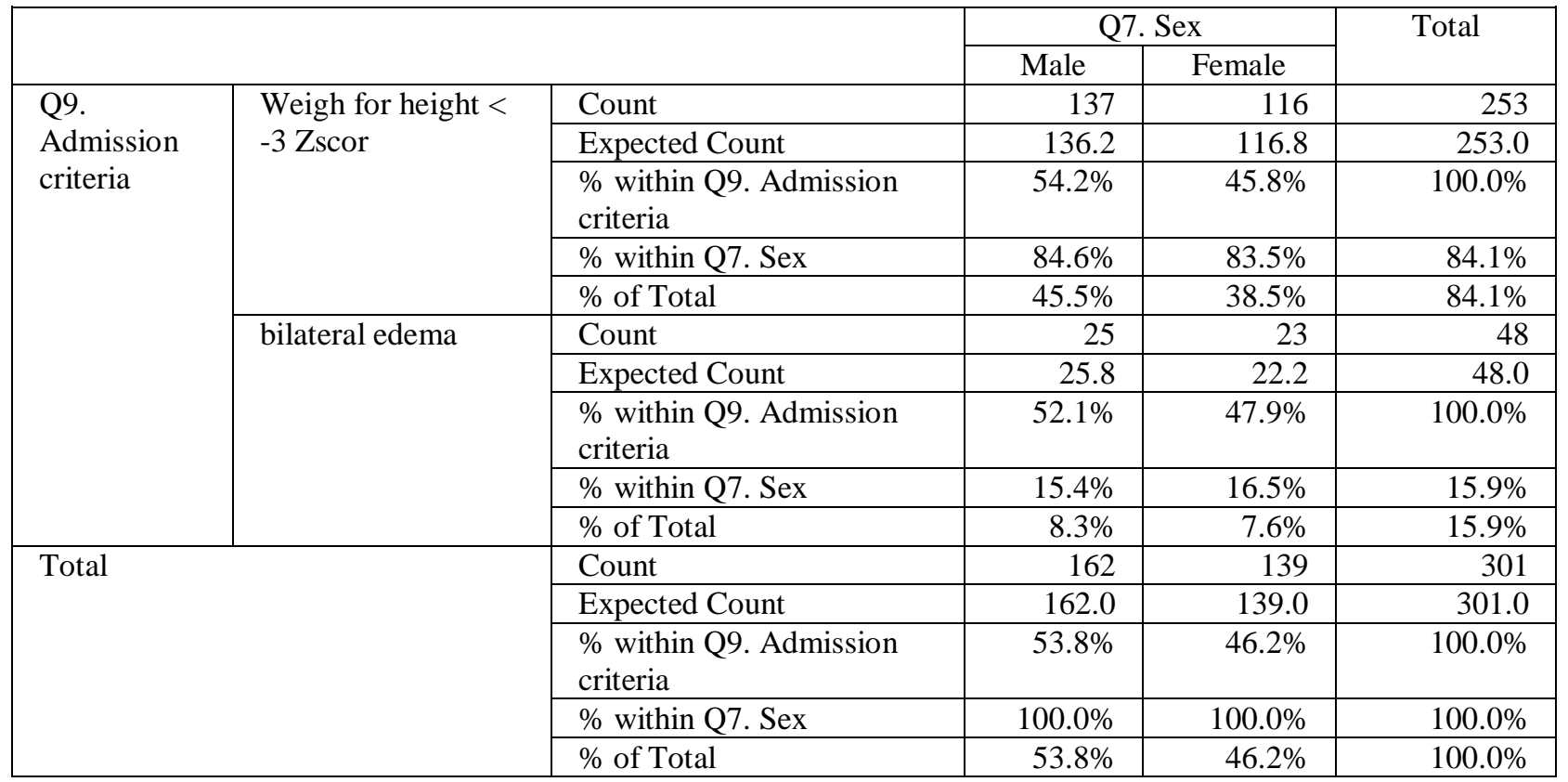

Table 4.21.1 Chi-Square

\begin{tabular}{|l|r|r|r|r|r|r|}
\hline & \multicolumn{1}{|c|}{ Value } & df & $\begin{array}{c}\text { Asymptotic } \\
\text { Significance (2- } \\
\text { sided) }\end{array}$ & $\begin{array}{c}\text { Exact Sig. (2- } \\
\text { sided) }\end{array}$ & $\begin{array}{c}\text { Exact Sig. } \\
\text { (1-sided) }\end{array}$ & Point Probability \\
\hline Pearson Chi-Square & $.069^{\mathrm{a}}$ & 1 & 0.792 & 0.875 & 0.457 & \\
\hline N of Valid Cases & 301 & & & & & \\
\hline
\end{tabular}

According the Chi-Square statistic test, since P-value is greater than 0.05 (Exact Sig. (2-sided) 0.875) there is no significant association between the type of malnutrition and gender.

\subsubsection{Type of malnutrition and birth weight}

\begin{tabular}{|c|c|c|c|c|c|}
\hline \multicolumn{5}{|c|}{ Birth weight } & \multirow[t]{2}{*}{ Total } \\
\hline & & & $\begin{array}{c}\text { low birth weight } \\
(<2500 \mathrm{~g})\end{array}$ & $\begin{array}{c}\text { Normal birth } \\
\text { weight }(>\text { or } \\
=2500 \mathrm{gr})\end{array}$ & \\
\hline \multirow{8}{*}{$\begin{array}{l}\text { Admission } \\
\text { criteria }\end{array}$} & \multirow{5}{*}{$\begin{array}{l}\text { Weigh for } \\
\text { height }<-3 \\
\text { Zscor }\end{array}$} & Count & 120 & 133 & 253 \\
\hline & & Expected Count & 116.8 & 136.2 & 253.0 \\
\hline & & $\begin{array}{l}\% \text { within Q9. Admission } \\
\text { criteria }\end{array}$ & $47.4 \%$ & $52.6 \%$ & $100.0 \%$ \\
\hline & & \% within Q8. Birth weight & $86.3 \%$ & $82.1 \%$ & $84.1 \%$ \\
\hline & & $\%$ of Total & $39.9 \%$ & $44.2 \%$ & $84.1 \%$ \\
\hline & \multirow{3}{*}{$\begin{array}{l}\text { bilteral } \\
\text { odema }\end{array}$} & Count & 19 & 29 & 48 \\
\hline & & Expected Count & 22.2 & 25.8 & 48.0 \\
\hline & & $\begin{array}{l}\% \text { within Q9. Admission } \\
\text { criteria }\end{array}$ & $39.6 \%$ & $60.4 \%$ & $100.0 \%$ \\
\hline
\end{tabular}




\begin{tabular}{|l|l|r|r|r|}
\hline \multirow{4}{*}{ Total } & \% within Q8. Birth weight & $13.7 \%$ & $17.9 \%$ & $15.9 \%$ \\
\cline { 2 - 5 } & \% of Total & $6.3 \%$ & $9.6 \%$ & $15.9 \%$ \\
\hline & Count & 139 & 162 & 301 \\
\cline { 2 - 5 } & Expected Count & 139.0 & 162.0 & 301.0 \\
\cline { 2 - 5 } & $\begin{array}{l}\text { \% within Q9. Admission } \\
\text { criteria }\end{array}$ & $46.2 \%$ & $53.8 \%$ & $100.0 \%$ \\
\cline { 2 - 5 } & \% within Q8. Birth weight & $100.0 \%$ & $100.0 \%$ & $100.0 \%$ \\
\cline { 2 - 5 } & \% of Total & $46.2 \%$ & $53.8 \%$ & $100.0 \%$ \\
\hline
\end{tabular}

According to Chi-Square statistic test, there is no significant association between the type of malnutrition and birth weight of children.

\begin{tabular}{|l|c|c|c|c|c|c|}
\hline \multicolumn{1}{|l|}{ Table 4.22.1 Chi-Square Tests } & Value & $\mathrm{df}$ & $\begin{array}{c}\text { Asymptotic } \\
\text { Significance (2-sided) }\end{array}$ & $\begin{array}{c}\text { Exact Sig. } \\
\text { (2-sided) }\end{array}$ & $\begin{array}{c}\text { Exact } \\
\text { Sig. (1- } \\
\text { sided) }\end{array}$ & $\begin{array}{c}\text { Point } \\
\text { obability }\end{array}$ \\
\hline Pearson Chi-Square & $1.000^{\mathrm{a}}$ & 1 & .317 & .346 & .200 & \\
\hline N of Valid Cases & 301 & & & & & \\
\hline
\end{tabular}

4.3.3 Education level of mother and immunization statue of children

\begin{tabular}{|c|c|c|c|c|c|c|c|c|c|}
\hline \multicolumn{10}{|c|}{ Table 4.23 Chi-Square Tests } \\
\hline & \multirow[t]{3}{*}{ Value } & \multirow{3}{*}{$\begin{array}{l}\mathrm{d} \\
\mathrm{f}\end{array}$} & \multirow{3}{*}{$\begin{array}{l}\text { Asymptotic } \\
\text { Significanc } \\
\text { e (2-sided) }\end{array}$} & \multicolumn{3}{|c|}{ Monte Carlo Sig. (2-sided) } & \multicolumn{3}{|c|}{ Monte Carlo Sig. (1-sided) } \\
\hline & & & & \multirow[t]{2}{*}{$\begin{array}{c}\text { Significanc } \\
\mathrm{e}\end{array}$} & \multicolumn{2}{|c|}{$\begin{array}{c}95 \% \text { Confidence } \\
\text { Interval }\end{array}$} & \multirow[t]{2}{*}{$\begin{array}{c}\text { Significanc } \\
\mathrm{e}\end{array}$} & \multicolumn{2}{|c|}{$\begin{array}{l}95 \% \text { Confidence } \\
\text { Interval }\end{array}$} \\
\hline & & & & & $\begin{array}{c}\text { Lowe } \\
r \\
\text { Boun } \\
d\end{array}$ & $\begin{array}{c}\text { Upper } \\
\text { Boun } \\
d\end{array}$ & & $\begin{array}{c}\text { Lowe } \\
\text { r } \\
\text { Boun } \\
d\end{array}$ & $\begin{array}{c}\text { Upper } \\
\text { Boun } \\
d\end{array}$ \\
\hline $\begin{array}{l}\text { Pearso } \\
\text { n Chi- } \\
\text { Square }\end{array}$ & $\begin{array}{r}20.989 \\
a\end{array}$ & 6 & .002 & $.000^{\mathrm{b}}$ & .000 & .010 & & & \\
\hline $\begin{array}{l}\mathrm{N} \text { of } \\
\text { Valid } \\
\text { Cases }\end{array}$ & 301 & & & & & & & & \\
\hline \multicolumn{10}{|c|}{ a. 7 cells $(58.3 \%)$ have expected count less than 5 . The minimum expected count is .28 . } \\
\hline \multicolumn{10}{|c|}{ b. Based on 301 sampled tables with starting seed 846668601.} \\
\hline \multicolumn{10}{|c|}{ 1. The standardized statistic is -3.167 . } \\
\hline
\end{tabular}

Graph 4.1:- Education level of mother and immunization statue of children 


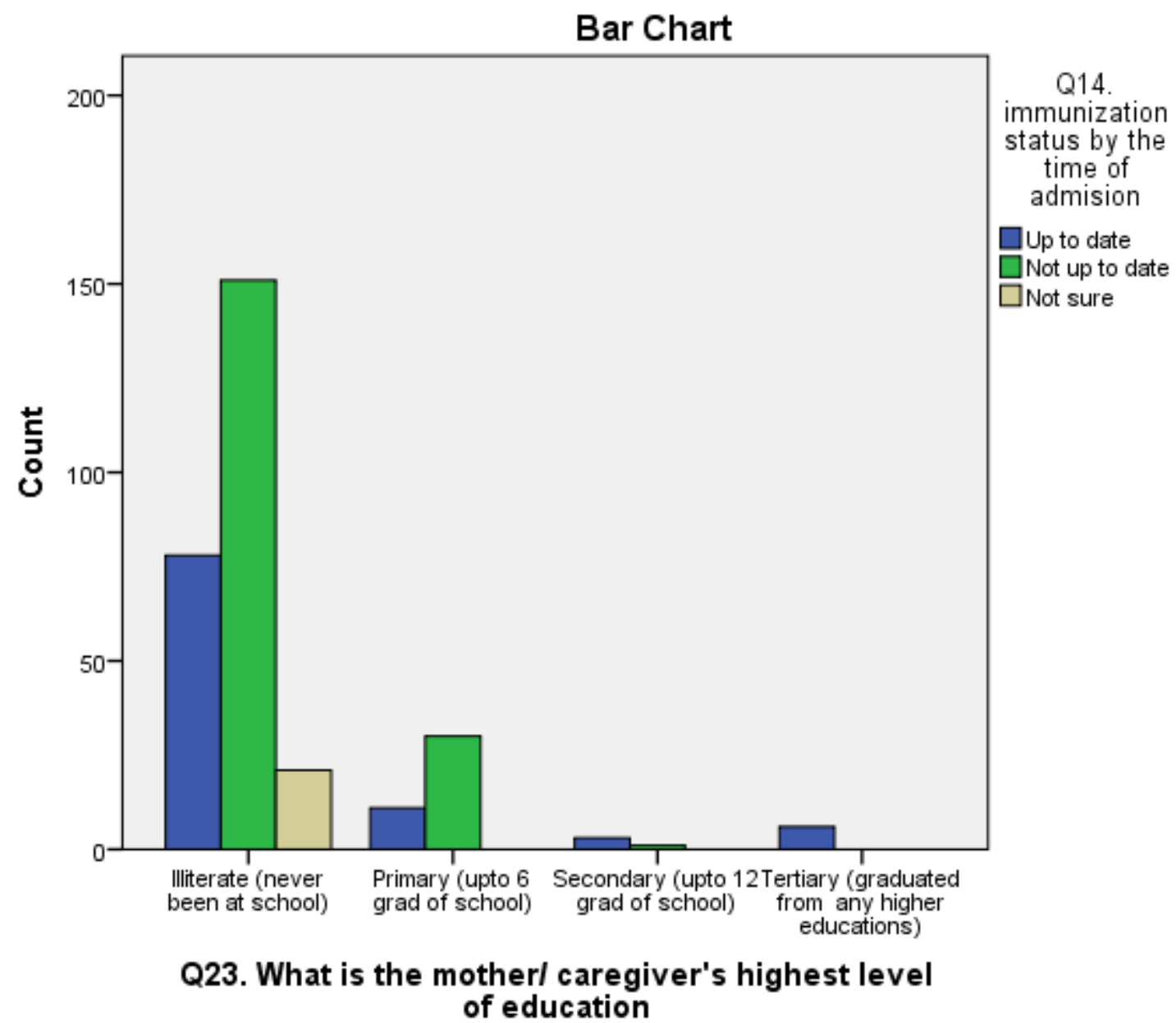

According the above mentioned Chi-Square statistic Tests, there is significant association between education level of mother and immunization status of children.

\section{Discussion of the Results:-} Introduction:-

In this section the results of the study will be discussed and where possible compared to the results of relevant studies of the same nature. The limitations encountered during the study will be discussed to evaluate to what extent they influenced the results

\section{Results:- \\ Socio-demographic information:-}

Total of 301 children under five year of age with severe acute malnutrition with their mothers/caretakers participated in the study admitted in three Therapeutic Feeding Unites located in Miwand and Indira Gandhi Child health hospitals of Kabul city and Parwan Provincial Hospital. Total of 132 out of 301participatns were from Indira Gandhi Child Health Hospital, 86 children from Miwand and 83 children from Parwan provincial Hospital located in Charikar city, the study is not national representative and covering only 3 out of 68 therapeutic feeding unites functioning in the entire country.

The study looked to children 0-59 months of age, the results of the study revealed that around $40 \%$ of them were children with $=<6$ month of age, while children aged from 7-12 months and 13-24 month contributing to $28.4 \%$ and $18.5 \%$ respectively.

The results of Afghanistan National Nutrition Survey 2013 also indicating that the most children aged with severe malnutrition were between 0-5 months of age. (Overall, 9.5\% (95\% CI 8.7-10.4) of children in 0-59 month of age in Afghanistan were wasted. Wasting was $13,2 \%$ (95\% CI 11.1-15.5) at 0-5 months old children). 
Rikimaru et al. (1998) determined the risk factors for developing severe malnutrition, underweight and low birth weight amongst children eight to 36 months old in the Princess Marie Louise Hospital in Accra, Ghana [14], found that severely malnourished children were more likely to have young mothers.

In this study the majority of mothers $(59.1 \%$ ) were reported old age (more than 21 years) while $34.2 \%$ of them reported had younger age (less than 21 years of age). about $83.1 \%$ of mothers reported were illiterate and $13.6 \%$ primarily education (up to 6 grad of school) and only $2 \%$ with tertiary education (graduation from any higher education).

According to the Afghanistan Living Condition Survey 2013/14 reports[15], adult literacy rate (15 years of age and over) at national level was $19 \%$ among women and $49.1 \%$ among men that mean, nationally only 19 percent of women 15 years and over are able to read and write, compared to 49 percent of for men. Falbo and Alves (2002) found that $15.2 \%$ of mothers of children hospitalized in the Institute Maternal Infantile de Pernambuco in Brazil were illiterate.

Educational levels of parents in Ghana and India with severely malnourished children were lower than that of parents with healthy children (Jeyaseelan and Lakshmana, 1997; Rikimaru et al., 1998) [16]. Christianson and Alderson (2001) found that female education had a positive and statistically significant effect on a child's nutritional status. Mothers with post-secondary schooling had fewer malnourished children than mothers with primary and secondary schooling. Mother's that were better educated fed their children better (Christianson and Alderson, 2001) [17].

In this study both boys and girls were affected by severe acute malnutrition while the prevalence among boys were slightly higher (53.8\%) with compare to girls (46.2\%). The Afghanistan National Nutrition Survey 2013[1] report also indicting boys $4.5 \%$ (<- 3 SD [95\% CI -3.9-5.22]) were more affected by wasting than girls (3.5\% <- 3 SD 95\% CI [2.93 -4.24]). Christiansen and Alderman (2001) [17] found that more boys than girls younger than five years old had malnutrition in Ethiopia. Mahgoub et al. (2006) [18] also found that in the age group of children zero to three years old in Botswana, malnutrition was more prevalent in males than in females.

\section{Anthropometric Information:-}

Birth weight is a predictor of malnutrition (Kleynhans et al., 2006) [19] and there is a direct link between maternal and child nutrition (Teller and Yimar, 2000) [20]. In a study done by Falbo and Alves (2002) [21] the median birth weight of children was $2.80 \mathrm{~kg}$. The study was done in Brazil between1999-2000 and $88.9 \%$ of the children with severe malnutrition were younger than six months and $42.4 \%$ had low birth weights (Falbo and Alves, 2002). In India, low birth weight is related to maternal nutritional factors such as energy and protein intake during pregnancy and the weight of the mother before she got pregnant (Ramakrishnan, 2004) [22]. Gupta (2008) found that low birth weight babies had a higher risk of developing feeding problems and malnutrition. [23]

In this study $46.2 \%$ of children reported had birth weight leas then 2500 grams which indicting low birthweight while $53.8 \%$ with normal birth weight( $>2500$ grm).

\section{Maternal information:-}

In this study almost $99 \%$ of mothers of the children were alive and only in one case the mother was death, $95 \%$ of children were cared by his/her mother and only $5 \%$ of them were cared by a caretaker mostly grandmother, meanly during his/her stay in the hospital. About $98.3 \%$ of mothers reported were married. In Afghanistan, culturally the child is cared by his/her mother and if the mother is not alive or busy with caring newly delivered babies, in most cases the grandmother has been taken the responsibility of the child.

Evidence from a study in Limpopo, South Africa amongst children 12 to 24 months of age showed that children had a lower risk of stunting if the mother was the caregiver (Kleynhans et al., 2006)[19]. In Nigeria 450 mothers were interviewed and $77 \%$ of mothers cared for their own children, while $23 \%$ of mothers had somebody that care for their children (Ogunba, 2008)[24].

In this study $17.6 \%$ of mothers had only one live birth (the child in the study), $27.2 \%$ had two live births, $18.9 \%$ had three live births, and $13.3 \%$ had four live births and $10.6 \%$ had 5 live births and $12.3 \%$ had more than 5 live births. According to Afghanistan Demographic \&Health Survey results 2015, total fertility rate among afghan 
women (15-49 year) reported as 5.3. A study undertaken by Teller and Yimar (2000) [20] in Ethiopia amongst mothers 15 to 49 years old and children younger than five years old, showed the highest rate of stunting in children with a birth order of four or five $(54 \%)$ and then a birth order of six or more $(53 \%)$.

\section{Other disease along with severe acute malnutrition:-}

In this study $84.1 \%$ of children were wasted and $15.9 \%$ with bilateral petting edema. Out of 301 children, $24.9 \%$ reported had a disease along with malnutrition, $16.3 \%$ had diarrhea, $5.3 \%$ Pneumonia and $1 \%$ Congenital Heart Disease. According to the Afghanistan National Nutrition Survey 2013 results [1], $12.8 \%$ of children under five years of age with wasting reported Diarrhea in last two weeks of the time of survey and $13.5 \%$ of Acute Respiratory Illness (Pneumonia) in the last two weeks of the time of survey.

A study by Saloojee et al. (2007)[25] undertaken in Limpopo, South Africa amongst children younger than five years old, also showed that malnourished children had been admitted to hospital on previous occasions (38\%). There was a close to significant association between marasmus, kwashiorkor and previous admittance to hospital for episodes of diarrhea, with $57 \%$ of children having been admitted to hospital previously for diarrhea. Children had been admitted once before (45\%), some were admitted for the first time (26\%) and some admitted three times before $(23 \%)$.

\section{Immunization and feeding practices:-}

In this study $32.6 \%$ of mothers reported completed their child immunization but $60.5 \%$ had not completed routine vaccinations of the child. Out of 301 children participating in the study, the majority of the children $88.4 \%$ were breastfed during the first 6 months of age, while $11.6 \%$ were reported never breastfeed. Total of $44.5 \%$ children reported start complementary feeding during the first 3 month of age while $26.9 \%$ started complementary feeding between 4-5 months of age and only $19.9 \%$ of children with age of 6-8 months which is the exact time for starting appropriate complementary feeding to the child, while $8.6 \%$ between $9-12$ months of age.

According to Afghanistan Demographic \& Health Survey 2015 report [26], overall, 46 percent of children have received all basic vaccinations. Seventy-four percent of children have received BCG, 73 percent have received the first dose of pentavalent, and 85 percent have received polio 1. Fifty-eight percent and 65 percent of children have received the third dose of the required three doses of the pentavalent and polio vaccines, respectively. Coverage of vaccination against measles is 60 percent for the first dose. Thirteen percent of children in Afghanistan have not received any vaccinations. The same report indicating that only $43 \%$ of the infants under age 6 months were found to be exclusively breastfed. In addition to breast milk, $10 \%$ of infants consume plain water, 2 percent consume nonmilk liquids, $28 \%$ consume other milk, and 14 percent consume complementary foods. $19 \%$ of infants under age 6 months are fed using a bottle with a nipple. $56 \%$ of children age 6-8 months receive timely complementary foods, and one-third (33 percent) of children age 18-23 months have been weaned.

Teller and Yimar (2000) [20] undertook a study in Ethiopia amongst children younger than five years and found that exclusive breastfeeding for longer than six months is often a cause of malnutrition as the breast milk or other fluids being given to the children are not sufficient to meet the energy and nutrient requirements for a child older than six months of age. On the other hand, a lack of exclusive breastfeeding can cause stunting (Teller and Yimar, 2000).

According to the WHO recommendation, exclusive breastfeeding from birth up to 6 month and starting of appropriate complementary feeding after that with continuation of breastfeeding up to 2 years of live is a key strategy on optimal nutrition of children 0-24 month of age, introduction of complementary feeding early and late from 6 month of age is a predisposing condition for child malnutrition.

In this study majority of children were introducing complementary feeding before 6 years of age which can be a main factor of causing the child malnutrition.

\section{Attendance to Antenatal care visits \& maternal knowledge:-}

In this study only $27.2 \%$ of mothers reported have participated at least 3 antenatal visits during pregnancy with the current child while $72.8 \%$ women had less than 3 or no antenatal visits at all. About $17.3 \%$ of mothers received information /education on diarrhea in the clinic, while other topics including $13.3 \%$ about healthy eating, 21.9 \%about breastfeeding, $5.6 \%$ about complementary feeding and almost less than $2 \%$ about food fortification and growth monitoring. Antenatal care (ANC) from a skilled provider is important to monitor pregnancy and reduce 
morbidity and mortality risks for the mother and child during pregnancy, at delivery, and during the postnatal period.

The AfDHS (Afghanistan Demographic \& Health survey) 2015 [26] results show that 59 percent of women who gave birth in the 5 years preceding the survey received antenatal care from a skilled provider at least once for their last birth. $18 \%$ of women had four or more ANC visits. Urban women were more likely than rural women to have received ANC from a skilled provider (72 percent and 55 percent, respectively) and to have had four or more ANC visits (32 percent and 14 percent, respectively). According to the Afghanistan National Nutrition Survey 2013 results[1], during ANC visits, 47.7\% women received information/counseling about eating more nutritious food followed by advisement to take extra rest (42.3\%) and information/ counseling about exclusive breast feeding (15.5\%). Almost $21.9 \%$ women did not receive any relevant/kind of information/counseling during visits.

In a study undertaken in India amongst children younger than four years old also showed no significant difference in health practices between mothers of malnourished and well-nourished children. The health practices were often based on traditional beliefs and mothers did not believe in medical care for childhood illnesses (Saito et al., 1997) [27].

\section{Household information:-}

According to a Survey of the Afghan People by The Asia Foundation in 2015, [28] reported that the average household monthly income in Afghanistan is 11,214 Afs (approximately 174 USD). Afghans who live in urban areas report higher monthly incomes (15,890 Afs, or USD 246) than residents of rural areas (9,672 Afs, or USD 150). There are significant regional variations in household income as well, ranging from 5,870 Afs (USD \$91) in the Central/Hazarajat region to 16,195 Afs (USD 251) in the Central/Kabul region. Afghans who have more education are significantly more likely to report higher monthly household income than those with less education. The World Bank also reported in 2015, Afghanistan is one of the most impoverished nations in Asia. With 36\% of its population living below the poverty line Afghanistan is only second to Bangladesh as Asia's poorest country. Poverty is most heavily concentrated in the rural areas of Afghanistan.

In this study, $49.2 \%$ of mothers reported their household monthly income were between 6001-10000 Afs( 89 -150 USD) and about $22.6 \%$ reported monthly income from 3001-6000Afs(44-89 USD) while 19.9\%of women reported their household monthly income was from 10001-15000 Afs(150-224USD) while only $5.3 \%$ reported their monthly income from 15,001-20,000 (224 -300 USD) and 2,3\% above from 20001 Afs ( >300 USD). About 25\% of mothers reported their household income source is from regular wage /salary while $70.8 \%$ reported other sources and only around $4.2 \%$ of families used incomes from pension and disability sources.

The Afghanistan Demographic \& Health Survey report 2015[26] indicating that, the average size of households in Afghanistan is 8.0 persons. Urban households are slightly smaller than rural households (7.7 persons versus 8.2 persons). Men head most of Afghan households (98\%), with only $2 \%$ of households headed by women.

In this study about, $44.2 \%$ of women reported 7-9 family members depended on the income in the household, while another $37.5 \%$ reported $4-6$ and only $14 \%$ reported $10-12$ are dependent in the household. However, $82.1 \%$ mothers reported the child's father and $17.6 \%$ the father's in-law of the child and only $0.3 \%$ the mother of child were the heads of the household. Around $39.5 \%$ of mothers/caretakers in this study reported they are using dug well water and $29.6 \%$ and $28.2 \%$ reported stream and piped water respectively, and only $1.3 \%$ from spring water and $1.3 \%$ from other source of water for drinking and preparing of foods.

According to the Afghanistan Demographic \& Health Survey report 2015 [26], overall,65\% of households in Afghanistan have access to an improved source of drinking water.86 \% of urban households have access to an improved drinking water sources, in contrast to only $58 \%$ of rural households. As per the definition of improved source of drinking water, in the study, about $29.6 \%$ of household using stream water and $1.3 \%$ of household from other sources, are those have not access to an improved source of drinking water.

In South Africa about 56\% of households have a size of five to nine people stunted children often live in households that are bigger or have more people (Kleynhans et al., 2006) [19] and therefore the risk for stunting has been found to be highest in households with nine or more people in the household .In Ethiopian communities, 24\% of households with more than four children were malnourished (James et al., 1999) [29].The risk of children from a household in 
Zimbabwe and Ethiopia being stunted increased from $7 \%$ when it was only one child to $38 \%$ when the household had seven children younger than ten.

\section{Conclusion and Recommendations}

\section{Conclusion:-}

The results of this study indicated that the main factors that were associated with a child becoming malnourished were:

Socio-demographic information:

- $\quad$ around $40 \%$ of malnourished children participated in the study with the age of $=<6$ month

- About $34.2 \%$ of mothers reported had younger age (less than 21 years of age).

- The illiteracy rate among mothers were very high with $83.1 \%$ of mothers and $13.6 \%$ of mother had primarily education (up to 6 grad of school) and only $2 \%$ with tertiary education (graduation from any higher education).

- The prevalence of severe acute malnutrition among boys were slightly higher (53.8\%) with compare to girls $(46.2 \%)$.

- Majority of children (60.1\%) were reported delivered at home and only $38.6 \%$ delivered at any health facilities Anthropometric Information:

- About $46.2 \%$ of children reported were low birthweight (weight leas then 2500 grams)

Maternal information:

- almost $99 \%$ of mothers of the children were alive

- Most of the children (95\%) were cared by his/her mother and only 5\% by a caretaker mostly grandmother, meanly during his/her stay in the hospital, $98.3 \%$ of mothers reported were married.

- Most of the mothers with one live births (17.6\%), two live births (27.2\%), three live births (18.9\%), and four live births $(13.3 \%)$ participated in the study

Other disease along with severe acute malnutrition:

- Wasting a farm of severe acute malnutrition (W/H<-3 Zcore) was more prevalent ( $83.4 \%$ of children) than bilateral edema.

- Association of other disease were also reported along with severe acute malnutrition, diarrhea (16.3\%), Pneumonia (5.3\%) and congenital heart disease (1\%)

Immunization and feeding practices:

- Majority of children (60.5\%) were reported had not completed routine vaccinations

- Most of the children $88.4 \%$ were breastfed during the first 6 months of age, while $11.6 \%$ were reported never breastfeed.

- Almost $44.5 \%$ children reported start complementary feeding during the first 3 month of age and $26.9 \%$ other started complementary feeding between 4-5 months of age while $8.6 \%$ between $9-12$ months of age which are not the good time for starting the complementary feeding.

- $\quad$ only $19.9 \%$ of children start complementary feeding with age of 6-8 months which is appropriate time for starting complementary feeding

Attendance to Antenatal care visits \& maternal knowledge:

- $\quad$ Most of mothers (72.8\%) reported had less than 3 or no antenatal visits at all during pregnancy with her current malnourished child

- About three to four percent of mother do not have any knowledge/ information about key health and nutrition issues,

- $\quad$ Only $17.3 \%$ of mothers received information /education on diarrhea $13.3 \%$ about healthy eating, 21.9 \%about breastfeeding, $5.6 \%$ about complementary feeding and almost less than $2 \%$ about food fortification and growth monitoring, when visiting health facilities.

\section{Household information:}

- $\quad$ About half of participants (49.2\%) reported their household monthly income were between 6001-10000 Afs( 89 -150 USD), and small amount of families (2,3\%) above from 20001 Afs ( >300 USD) per month

- About $70.8 \%$ of families have other income sources than regular wage/salary, those are the families with unemployment head of family.

- About majority of families (44.2\%) reported 7-9 family members and only $14 \%$ reported 10-12 family members are dependent on monthly income in the household.

- Almost all families were headed by men ( $82.1 \%$ father and $17.6 \%$ father in-law of the child)

- $29.6 \%$ of families reported using stream and $1.3 \%$ from other sources of water for drinking and preparing of 
foods which are not an improved source of drinking water.

\section{Recommendations:-}

The Lancet journal in its series on maternal and child nutrition published in 2013, [30] proposes three levels of interventions to combat the problem of malnutrition among children. These interventions, in fact, address the immediate, underlying and basic causes of malnutrition, according to UNICEF Conceptual Framework on malnutrition and are categorized as:

a) Nutrition specific interventions: Includes interventions such as adolescent and pre-conception nutrition, maternal nutrition, micronutrients supplementation and food fortification, breastfeeding and complementary feeding, dietary supplementation for children, dietary diversification, feeding behaviors and stimulation, treatment of acute malnutrition, disease prevention and management and nutrition interventions during emergencies.

b) Nutrition sensitive interventions: Includes agriculture and food security, social safety net, early child development, maternal mental health, women's empowerment, child protection, classroom education, water and sanitation, health and family planning services.

c) Building enabling environment: Rigorous evaluation, advocacy strategies, horizontal and vertical coordination, accountability, incentives, legislations, and regulations; leadership programs; investment in capacity development and mobilization of domestic resources.

In consideration with above mentioned evidence-based interventions, the following recommendation has been proposed to improve the nutrition situation of children 0-59 months of age and decreasing the rate of children with severe acute malnutrition.

Nutrition specific interventions:-

The leading organization for implementation of nutrition specific interventions is the Ministry of Public Health.

- The Infant and Young Child Feeding (IYCF) program should be fully integrated in the current Basic Package of Health Services and Essential Package of Hospital Services, and key health facility staff including midwives and female doctors should be capacitated on IYCF practices to deliver key messages on exclusive breastfeeding up to 6 month, timely starting of appropriate complementary feeding with continuation of breastmilk up to 24 month of age to all mothers visiting health facilities during ANC and PNC services.

- Increase the capacity of community health worker (CHWs) on nutrition programs based on their job description

- Increase the number of health facilities with management of severe malnutrition (including both moderate and acute) services for children less than 5 years of age.

- Strengthening the micronutrient supplementation programs to pregnant women and children under five years of age. (Iron+ Folic acid supplementation for pregnant women, Vit A, Zinc and Multiple Micronutrient Powder for children).

- Capacitate all health care providers to deliver key nutrition specific intervention through all level of health facilities based on National and internationally acceptable guidelines and protocols.

- Increase the awareness of general people by delivering of key nutrition messages through deferent media channels

- Increase the coverage of routine immunization program through strengthening and expansion of vaccine outreach programs

- Support the production, distribution and consumption of fortified foods.

- Support the development of Mother Support Groups at villages to promote basic IYCF practices and help the mothers referred from health facilities.

- Initiate and implement interventions during first 1000 days of live (from conception up to 24 month after birth), window of opportunities to prevent premature births and improve cognitive, physical growth and development

\section{Nutrition sensitive interventions:-}

The implementation of nutrition sensitive interventions are leading by a number of key governmental organizations including, Ministry of Agriculture Irrigation and Livestock, Ministry of Rural Rehabilitation \& Development, Ministry of Education and others in coordination with Ministry of Public Health.

- Support women empowerment at household, community and society to take active part on key decision making, purchasing power, and education, by increasing the awareness of family and society elders. 
- Decreasing household food insecurity by initiating and implementing a number of income generation projects and programs (e.g. Poultry, kitchen gardening etc.)

- Integration of WAHS(Water Sanitation and Hygiene) interventions in to nutrition programs at health facilities

- Promoting hand washing with soap after defecation, before preparing food and feeding the child

- Increase the awareness of people on purification methods of drinking water and food safety through health facilities and communication campaigns

- Strengthening and expanding the use of family planning methods

\section{Building enabling environment:-}

For implementation of this interventions high ringing and senior decision making of the government including H.E president of the country are involved.

- Allocate specific budget for implementation of nutrition programs in the government budget system, while currently most of nutrition programs are funded by external donors

- Establishment and strengthining of Food Security and Nutrition Agenda as main platform for coordinating food security and nutrition intervention among relevant governmental and non-governmental organizations, which is designed to be led by H.E second vice president of Afghanistan.

- Support the development and implementation of food quality control and regulatory system, to ensure that the locally produced and imported foods are safe, nutritious and appropriate for human consumption

Also there is need for further nationally representative research to identify other risk factors contributing severe acute malnutrition among children 0-59 months of age.

\section{References:-}

1. Afghanistan National Nutrition Survey result 2013

2. World Health Organization, 2005. (Environmental Burden of Disease Series, No. 12).

3. WHO. Guideline: Updates on the management of severe acute malnutrition in infants and children. Geneva: World Health Organization; 2013

4. Risk Factors of Malnutrition among Children under Five Year of Age in Mohamed Alamin Paediatric Hospital (Dr. Siham Mohamd Osman Gritly1, Ahmed Mohamed Mohamed Albashir2, Asma Bashir Ali Ibrahim3) Khartoum Sudan

5. Severe Acute Malnutrition among Hospitalized Children, Aden, Yemen Mohammed Ali Badi, Iman Ali BaSaddik, Pediatric Department, Faculty of Medicine and Health Sciences, University of Aden, Aden, Yemen

6. Outcome in malnourished children at a tertiary hospital in Swaziland",[6] was conducted by Dr. Oscar Benyera in 2013, University of Pretoria

7. SOCIO-CULTURAL DETERMINANTS OF MALNUTRITION AMONG CHILDREN AGED BELOW 5 YEARS IN GARISSA SUB COUNTY, KENYA, 2016.

8. ACTORS INFLUENCING MALNUTRITION AMONG CHILDREN UNDER 5 YEARS OF AGE IN KWENENG WEST DISTRICT OF BOTSWANA, 2012, Authors, YANKINDA ETIENNE KADIMA

9. FOOD CONSUMPTION PATTERNS AND NUTRITIONAL STATUS OF CHILDREN (6-59 MONTHS) IN CAMPS OF INTERNALLY DISPLACED PERSONS IN WADAJIR DISTRICT, MOGADISHU-SOMALIA, FARHIA ABDIAZIZ SH.HUSSIEN, REG NO: Q57F/CTY/PT/20607/2012

10. ASSOCIATION BETWEEN MALNUTRITION AND FEEDING PRACTICE AMONGCHILDREN AGED SIX-TWENTY FOUR MONTHS AT MBAGATHI DISTRICT, HOSPITAL-KENYA, 2014

11. PERCEIVED SOCIO-CULTURAL FACTORS INFLUENCING NUTRITIONAL STATUS OF CHILDREN BELOW 5 YEARS IN SELECTED RURAL COMMUNITIES IN ENUGU STATE BY NNABUENYI CHINYELU J.P. 2015

12. Immediate Risk Factor Associated with Child Malnutrition in Ghana; A Critical Analysis of the Ashiedu Keteke Sub-Metro Area in Accra, 2010 , Abena K. Sarpong, Smart A. Sarpong, Christian Obirikorang , N. N. N. Nsowah-Nuamah

13. Determinants of Severe Acute Malnutrition among Under Five Children in Shashogo Woreda, Southern Ethiopia: A Community Based Matched Case Control Study, 2014

14. Rikimaru et al. (1998) the risk factors for developing severe malnutrition, underweight and low birth weight amongst children eight to 36 months old, Princess Marie Louise Hospital, Accra, Ghana

15. Afghanistan Living Condition Survey 2013-2014 reports

16. (Jeyaseelan and Lakshmana, 1997; Jeyaseelan, L. and Lakshman, M. 1997. Risk factors for malnutrition in south Indian, children. Journal of Biosocial Science. Vol. 29. No.1. pp.93-100Rikimaru, T., Yartey, J.E., 
Taniguchi, K., Kennedy, D.O. and Nkrumah, F.K. 1998. Risk factors for the prevalence of malnutrition among urban children in Ghana. Journal of Nutritional Science and Vitamin ology.

17. Christiaensen, L. and Alderman, H. 2001. Child Malnutrition in Ethiopia

18. Mahgoub, S.E.D., Nnyepi, M. and Bondeke, T. 2006. Factors affecting prevalence of malnutrition among children under three years of age in Botswana. African Journal of Food, Agriculture, Nutrition and Development. Vol. 6

19. Birth weight is a predictor of malnutrition (Kleynhans et al., 2006) Kleynhans, I.C., MacIntyre, U.E. and Albertse, E.C. 2006. Stunting among young black children and the socio-economic and health status of their mothers/caregivers in poor areas of rural Limpopo and urban Gauteng - the Nutri Gro Study. South African Journal of Clinical Nutrition.

20. Teller, H. and Yimar, G. 2000. Levels and determinants of malnutrition in adolescent and adult women in Southern Ethiopia. Ethiopian Journal of Health Development. Vol.14

21. Falbo, A.R. and Alves, J.G. 2002. Severe malnutrition: epidemiological and clinical characteristics of children hospitalized in the Institute Materno Infantil de Pernambuco,Brazil. Cadernos de Saúde Pública. Vol.18. No.5. PP.1473-7[22] Ramakrishnan, U. 2004. Nutrition and low birth weight: from research to practice. The American Journal of Clinical Nutrition. Vol. 79.

22. Gupta, R.K. 2008. Care of low birth weight neonates. JK Science: The Journal of Medical Education and Research. Vol. 10

23. Ogunba, B.O. 2008. Psychosocial care in complementary feeding of children: a Comparative study of the urban and rural community in Osun state, Nigeria: http://www.informaworld.com/smpp/content $\sim$ content

24. Saloojee, H., De Maayer, T., Garrenn, M.L. and Kahn, K. 2007. What's new? Investigating risk factors for severe childhood malnutrition in a high HIV prevalence South Africa setting 1. Scandinavian Journal of Public Health. Vol.35

25. Afghanistan Demographic \& Health Survey 2015 report, (AfDH2015)

26. Saito, K., Korzenik, J.R., Jekel, J.F. and Bhattacharji, S. 1997. A case-control study of maternal knowledge of malnutrition and helath-care-seeking attitudes in rural South India. Yale Journal of Biology and Medicine. Vol. 70

27. Afghan People Survey by the Asia Foundation, 2015

28. James, W.P.T., Ferro-Luzzi, A., Sette, S. and Mascie-Taylor, C.G.N. 1999, Ethiopia

29. Lancet journal, maternal and child nutrition, 2013. 